\title{
ZNAČAJ UPOTREBE DIGITALNE KOMUNIKACIJE U PROMOCIJI KULTURNOG NASLEĐA - PRIMER GRADA NOVOG SADA
}

\author{
Jelena Gajić, \\ Ivana Brdar, \\ Jelena Stanković, \\ Radmila Živković \\ Univerzitet Singidunum, \\ Beograd, Srbija
}

\begin{abstract}
Rezime:
Kulturni turizam se smatra najbrže rastućim segmentom turističkog tržišta posebno evropskog. Kultura se sve više koristi u promotivnoj strategiji za privlačenje turista nudeći bogatu autentičnu turističku ponudu. Novi informatički i tržišni trendovi diktiraju i nove načine komunikacije između tržišta i ciljne grupe tako da, digitalni marketing omogućava direktniju i aktivniju interakciju između turista, turističkih proizvoda i destinacija. Cilj rada je da se prikaže odnos kulture, kulturnog nasleđa i razvoja turizma uz podršku savremenih marketinških komunikacija. Kultura kao društveno nasleđe određene grupe ljudi, zajednice ili društva poslednjih decenija snažno utiče na razvoj turizma u mnogim destinacijama, a novi informatički i tržišni trendovi diktiraju nove načine komunikacije između tržišta i ciljne grupe. Digitalni marketing pruža interaktivnost i nudi personalizovane usluge turistima. U radu je predstavljen primer projekta u razvoju, primer digitalne komunikacije sa informatički "povezanim" turistima, odnosno značaj korišćenje digitalnih medija kako bi se postigla konkurentska prednost i bolje pozicionirala kulturna ponuda Novog Sada na globalnom turističkom tržištu.
\end{abstract}

Ključne reči:

kulturno nasleđe, turizam, digitalni marketing, društveni mediji

UVOD

Kretanje ljudi podstaknuto kulturnim atrakcijama, sa motivima prikupljanja novih informacija i iskustava kako bi zadovoljili svoje potrebe za kulturom jedna je od definicija kulturnog turizma. (Du Cros and McKercher, 2015; Mihić et al., 2014.). Kulturno nasleđe predstavlja kreativni deo dinamičnog okruženja koji dobija sve veći značaj za privredni razvoj društva. Kao deo smart turizma, pored održivosti, digitalizacije, i pristupačnost, kulturno nasleđe predstavljaju značajan potencijal, za kreiranje turističkih doživljaja .Kulturni turizam ima ogroman potencijal za rast ina to ukazuju činjenice da $40 \%$ ukupnog evropskog (http://ec.europa.eu/growth/sectors/tourism/offer/cultural_en) ali i svetskog turizma (http://www2.unwto.org/webform/survey-big-data-and-cultural-tourism) čini kulturni turizam tj. 4 od 10 turista bira destinaciju pre svega zbog autentične kulturne ponude. Kulturni turizam jedan je od vodećih oblika turizma koji ima širok dijapazon ponude od materijalnih (kulturo- istorijskih, arheoloških,
Correspondence:

Jelena Gajić

e-mail:

jgajic@singidunum.ac.rs 
arhitektonskih, etnografskih, umetničkih, sakralnih i profanih spomenika, itd.) do nematerijalnih resursa (hodočašća, verske svetkovine, običaji, tradicije, festivali, manifestacije, nacionalna i lokalna hrana i piće) i u mnogim zemljama nedovoljno iskorišćenih (www.unesco.org). Svakako, postoji potreba za razvojem i promovisanjem ovog vida turizma ali istovremeno i potreba da se obezbedi očuvanje kulturno- istorijskih mesta, spomenika, lokalne tradicije, jezika, običaja, itd.

Više nego ikada za privlačenje turista neophodno je implementirati nove tehnologije, kako bi kvalitetna turistička ponuda pružila više od tradicionalnih jer savremeni turisti u eri digitalnog sveta će svoju odluku o putovanju doneti na osnovu više parametara. Primena marketinga u kulturnom turizmu i strateško planiranje aktivnosti, predstavlja neophodnost savremenog poslovanja jer marketing treba sa jedne strane da obezbedi ekonomski benefit zajednici, gradu, destinaciji tj. bolji kvalitet života lokalnog stanovništva a sa druge strane treba da obezbedi kvalitetno, autentično iskustvo turistima/posetiocima (McCamley and Gilmore, 2016; Du Cros and McKercher, 2015).

Pitanje strateškog razvoja turizma jedne destinacije povezano je sa razumevanjem sve raznovrsnijih, personalizovanih potreba turista i njihovih očekivanja a sa druge strane usvajanjem inovacija u promotivnim aktivnostima. Sagledavanjem navedenog, uz pomoć digitalizacije moguće je kreirati atraktivne kulturne turističke proizvode koji će od malih „neotkrivenih“ destinacija i neiskorišćenih potencijala stvoriti novu turističku ponudu. Sinergijom turističke i kulturne-kreativne industrije (Cultural and Creative Industry-CCIs) (Lond and Morpeth, 2016; McKercher and Du Cros, 2012.) i strateški organizovana komunikaciona strategija podrazumeva uključivanje digitalne tehnologije koja obezbeđuje da se iskustvo putovanja može "kupiti" jednim klikom. Video snimci, fotografije, online blogovi i razni sajtovi nude brojne informacije, utiske, iskustva koji povezuju turiste sa drugim ljudima (stanovnicima, drugim turistima) i mestima lako, brzo i bez velikog angažovanja.

Srbija treba da vidi šansu u bogatim i raznovrsnim kulturnim i turističkim potencijalnima, sa ciljem da privuče potencijalne domaće i inostrane turiste i poboljša svoju poziciju i imidž u svetu. Potrebno je istaći da su gradovi oduvek bili interesantni turistima, samo su se motivi poseta menjali. Danas, mnogi od njih žele da putuju, da osete, iskuse realnost autentičnih lokanih kultura što se smatra komparativnom prednošću u turističkoj ponudi jedne zemlje. (Kolb, 2017). Novi Sadje učinio značajne pomake u savremenom načinu prezentacije kulture s obzirom da je izabrana za kulturnu prestonicu Evrope za 2021. godinu. Skupština Grada Novog Sada, na VI sednici (2. septembra 2016.) donela je Strategiju kulturnog razvoja Grada Novog Sada za period 2016-2026. godine (http://novisad2021.rs/kulturna-strategija/). Definisali su politiku i programe u okviru kulturnog turizma, a koji su namenjeni promotivnom nastupu na međunarodnom nivou, daljem razvoju i unapređenju kulture i kulturnog turizma grada.

\section{SINERGIJA KULTURNOG NASLEĐA I TURIZMA}

Turizam sve više zahteva sjedinjenje sa segmentom kulture, zato se sa razlogom smatra da su pojmovi turizam i kultura usko povezani (Du Cros and McKercher, 2015; McKercher and Du Cros, 2012), da se upotpunjuju kao i da osim kulture i kulturna baština značajno doprinosi atraktivnosti turističke destinacije. Kultura i kulturna baština Evrope motivisala je turiste širom sveta da se upoznaju sa autentičnim nasleđem Evrope. Godina 2018. proglašena je evropskom godinom kulturne baštine ("Our heritage. Where the past meets the future!"),i upravo ta mesta susreta su polazna osnova za osmišljavanje i organizovanje brojnih događaja na lokalnom, nacionalnom i regionalnom nivou kako bi što originalnije približili svoja kulturna dobra turistima. (http://www. culturaltourism-network.eu/). Projekat je imao za cilj da naglasi bogatstvo i raznolikost evropskih kultura, da učini da stanovništvo u Evropi da osete pripadnost zajedničkoj kulturnom okruženju, da doprinese da kultura utiče na razvoj gradova. Svakako da kulturni događaji mogu doprineti obnovi gradova, destinacija, poboljšati međunarodnu pozicioniranost na turističkim tržištima, unaprediti imidž grada u očima turista, posetilaca ali i lokalnog stanovništva. (https://ec.europa.eu/programmes/creative-europe/actions/capitals-culture_en)

Da se ozbiljno pristupa razvoju kulturnog turizma, svedoči podrška od strane European Commission projektima kao što su: Wine Senses, The Roman Emperors Pilgrims route an innovative transnational combined cultural and cycling tourism product, Film festivals And Movie tourism across Unesco Sites, Development of transnational, creative and cultural tools for travellers along the Ways of Saint James...(https://ec.europa.eu/ docsroom/documents/29223). 
Kulturno nasleđe može biti opipljive forme, kao što su: građevine, spomenici, nošnje, knjige, istorijski gradovi, arheološka nalazišta ali i neopipljive forme kao što su: veštine, znanje, jezik, običaji, umetnost ali i flora, fauna i prirodno okruženje. Tehnološke inovacije su dale novu dimenziju kulturnom nasleđu kroz digitalne forme koje sve navedene forme "pretvaraju” u digitalnu umetnost ili animacije (Nosrati et al., 2018; Maurer,2015, Mihić et al., 2014) u funkciji promocije i očuvanja autentičnih tekstova, slika, video zapisa, itd. ( https://europa.eu/cultural-heritage/about).

U toku posete nekoj destinaciji turisti procenjuju u kojoj meri lokalno stanovništvo i samo mesto svojom ponudom oslikavaju i prenose kulturni imidž. Festivali, slušanje priča (story telling), (Nosrati et al., 2018) degustacija lokalne hrane, pijace, rukotvorine kao i ostali forme nematerijalne kulture jednog destinacije predstavljaju dobre argumente za dublje povezivanje i razumevanje lokalne kulture. (DuCros and McKercher, 2015).

Zahvaljujući savremenim izvorima informisanja i virtuelnim stimulansima, savremeni turisti su dodatno motivisani da posećuju nove destinacije, gradove, da upoznaju različite kulture. Današnji turisti su zahtevniji, obrazovaniji i uz pomoć digitalnih medija, jednostavno mogu da dođu do potrebnih informacija o željenim destinacijama, smeštajnim kapacitetima, različitim uslugama, kulturnim aktivnostima, sami kreiraju i rezervišu aranžmane, komentarišu, promovišu ili kritikuju dobijenu uslugu (Kolb, 2017; Maurer, 2015).

\section{DIGITALNI MARKETING I KULTURNI TURIZAM}

Digitalno okruženje je neminovnost savremenog čoveka (GPS, online naručivanje proizvoda/usluga, slanje poruka, pregled vesti, vremenske prognoze...) koji ne može da obavi svoje poslovne i privatne obaveze ako nije „konektovan“. Danas, turisti koriste istu digitalnu tehnologiju kako bi planirali putovanja, pronašli jedinstvena iskustva, povezali se sa članovima lokalne zajednice i emotivno približili lokalnom stanovništvu. (Kolb,2017). Digitalizacija ima višestruke koristi: značajna je za prezentaciju kulturnog nasleđa na Internetu, doprinosi zaštiti kulturnih dobara, omogućava istraživanja, edukaciju i širenje informacija većem broju zainteresovanih ciljnih grupa.

Tradicionalni kanali komunikacije se zamenjuju novim platformama, komercijalnim, interaktivnim sajtovima, sajtovima društvenih medija a sve u cilju da se brže i efikasnije dođe do potrebnih informacija. Turisti žele informacije o cenama, signalizaciji, hotelima, izletima, vremenskoj prognozi, istoriji mesta, religiji i običajima koji su aktuelni na destinaciji (Nosratiet al.2018;Maurer, 2014). Svakako, dobro osmišljena komunikacija može da motiviše potencijalne turiste da posete mesto a zatim da ih to pozitivno iskustvo "mobiliše " u promotera destinacije, kroz objave, asertivne komentare a rezultat svega toga je da je destinacija postala turistički proizvod („As a result, the traveler is now defining the city as a product“) (Kolb, 2017).

Prema Delgado (2017), turisti koji su motivisani da posećuju kulturna nasleđa smatraju se kreativnim turistima (Manrai et al., 2017) i oni očekuju od putovanja da se „dublje“ povežu sa okruženjem, kulturom, lokalnim stanovništvom, atmosferom na toj destinaciji (Du Cros and McKercher; 2015, McKercher and Du Cros, 2012). Ta konekcija se postiže jednim delom putem društvenih medija, tako da se može reći da se realni fizički i virtuelni svet prepliću u prostoru. Interakcija sa lokalnim stanovništvom predstavlja deo turističkog iskustva, ne samo tokom posete već i pre i posle. Društveni mediji čine ovu interakciju dinamičnom i uvek mogućom. S obzirom da turistički proizvod čini ne samo turistička atrakcija, već i turističke usluge i cela zajednica, posetioci će osetiti grad i zatim objaviti svoje utiske online i na taj način učestvovati u kreiranje imidža grada/destinacije (Kolb, 2017).

Upotreba novih tehnologija povećava kvalitet turističkog iskustva, privlači nove turiste, inicira stvaranje novih usluga, promoviše i povećava vidljivost kulturnog turizma, ne samo potencijalnim turistima već i drugim stejkholderima. Primer interesantnog projekta „Development of transnational, cerative and cultural tooks for travellers along the Ways of Saint James" koji koristi prednosti savremenih tehnologija, dobru inovativnu praksu kao i kulturne i kreativne instrumente (CCIs tools) sa ciljem razvoja turizam. Primena novih tehnologija Geolocation maps, 3D digitalisation, Augmented reality, Immersive tools, 360 images and videos, Travellers' advisor app, Electronic credentials card iMultimedia tools omogućava turistima da se upoznaju u svakom trenutku sa ažuriranim informacijama o kulturnom nasleđu i turističkim potencijalima, da unaprede kvalitet turističkog iskustva, stvara nove usluge i čini ih konkurentskim na globalnom turističkom tržištu.(https:// ec.europa.eu/docsroom/documents/29223). 
Jedan od načina da se promoviše kulturna vrednost grada, da se podstakne interes turista da upoznaju kulturu jednog grada, omogućava i tehnologija zasnovana na razdaljini (proximity-based technology system, iBeacons ${ }^{1}$ ). Interesantan projekat „digitalne priče“ o kulturi grada Hamilton u Kanadi je u stvari iBeacons aplikacija koja omogućava turistima, čim se približe odredištu, da dobiju automatski informacije tj. „priče“ o kulturi i istoriji željene destinacije/mesta. Ova tehnologija, osim što omogućava brži i kvalitetniji pristup informacijama o kulturnom nasleđu takođe povećava i kvalitet interakcije između korisnika i kulturnog objekta. Story telling" aplikacija treba da privuče pažnju novih posetilaca, probudi emocije, podstakne povezivanje sa odabranim odredištem. Sve navedeno bi trebalo da putovanje kroz grad posetiocima učini nezaboravnim, originalnim iskustvom, i da kroz "priče" izgradi njihovu trajnu vezu sa destinacijom; da kreira pozitivan imidž o kulturi grada. (Nosrati et al., 2018)

Digitalizacija kulturnog turizma ima višestruke benefite za: institucije kulture (promocija, materijalnih i nematerijalnih kulturnih dobara, povećanje broja turista, posetioca, diverzifikacija ciljnih grupa), kreativne industrije (kreiranje inovativnih turističkih usluga), bolje povezivanje stejkholdera, predstavlja šansu za mala i srednja preduzeća koja su aktivna u sektoru turizma da dopune svoju ponudu kulturnim sadržajem i tako se bolje pozicioniraju na tržištu, zatim za turiste (da planiraju i obliku putovanja u skladu sa svojim željama i da prikupe dodatne informacije u cilju da posete lično ili virtuelno željenu destinaciju (Maurer, 2015; Athena Plus, 2014). Biblioteke bi trebalo da budu lideri, inicijatori, garanti u digitalizaciji kulturnog nasleđa s obzirom da su institucije koje sakupljaju i čuvaju pouzdane i proverene informacije.

\section{DIGITALIZACIJA KULTURE GRADA NOVOG SADA}

S obzirom na to da je turistička industrija jedan od prioriteta ekonomskog razvoja Republike Srbije svakako treba istaći da je njeno bogato kulturno nasleđe neiskorišćeno u ovom smislu; ne samo destinacija već i pojedinačnih gradova (Beograd, Novi Sad, Niš, Sremska Mitrovica, Sremski Karlovci, Vranje, itd.)

Novi Sad je dobio dve titule(Evropska prestonica kulture za 2021. i Evropska prestonica mladih za 2019.) i mogućnost da „oživi“ kulturnu i kreativnu ponudu grada; da predstavi turističku ponudu grada na globalnom turističkom tržištu, „probudi“ svest lokalnog stanovništva, posebno mladih iz lokalne zajednice Novog Sada o viševekovnom prirodnom, kulturno-istorijskom i turističkom potencijalu Novog Sada; da podstakne njihovo angažovanje u kreativnim industrijama baziranih na digitalizaciji.

Po ugledu na evropske gradove, u gradu Novom Sadu se organizuje veliki broj manifestacija od kojih je najpoznatiji muzički festival u Jugoistočnoj Evropi EXIT, koji za četiri dana poseti u proseku oko 200.000 posetilaca.(https://www.exitfest.org/sr/news/sve-o-exitu-2018) Zatim, Cinema City, međunarodni festival sa bogatim filmskim, muzičkim i akademskim programom; Festival Novosadske muzičke svečanosti (NOMUS) kao i Zmajeve dečije igre - najpoznatiji festival dečje književnosti koji obuhvata multimedijalne programe za decu i mlade. Svake godine u Novom Sadu se organizuje i Festival uličnih svirača, Internacionalni festival alternativnog novog teatra u Srbiji (INFANT), Sterijino pozorje, Novosadski džez festival, Međunarodni festival proze PROSEFEST, EURO-IN FILM itd. (http://novisad2021.rs/novisad). Pored brojnih manifestacija, posebno treba izdvojiti Maticu srpsku, najstariju srpsku kulturnu i naučnu instituciju, temelj srpske kulturne baštine koja zajedno sa muzejima, galerijama, pozorištima i manifestacijama predstavlja bogatu autentičnu turističku ponudu, osnov kreativne platforme nove evropske prestonice kulture za 2021. godinu.

S obzirom na istorijske i kulturne tradicionalne veze sa evropskim kulturnim prostorom, Novi Sad uz pomoć digitalizacije, kulturnu baštinu želi da učini dostupnijom ne samo za svoje građane već za sve posetioce ovoga grada. Ciljevi aktuelnih projekata su bolje predstavljanje kulturnih vrednosti Novog Sada i njihove valorizacije kroz turističku ponudu integrisanu u ambijent kulturnog turizma zemalja Evropske Unije a čiji bi glavni nosioci bili mladi. (http://novisad2021.rs/bbns-digitalizacija-ubrojcavanje-k/).Realizacija digitalizacije grada Novom Sada će se intenzivirati narednih meseci a projekat koji je aktuelan je sajt na kome bogata kulturno istorijska baština grada Novog Sada može da se pretražuje po mestu, vremenu i sadržaju.(www.bbns.rs)

1 Location-based services (iBeacons) postaju popularan i snažan promotivan instrument sa visoko kvalitetnim i vremenski podešenim informacijama.

Introduced by Apple Inc. in 2013, iBeacons are one of the leading proximity beacon devices available in the market today; they operate using Bluetooth Low Energy and can transmit data from an object to a user's mobile device over short distances of no more than 70 meters (Burzacca and Paterno., 2014). 
Slika 1. Sajt Kulturne baštine Novog Sada

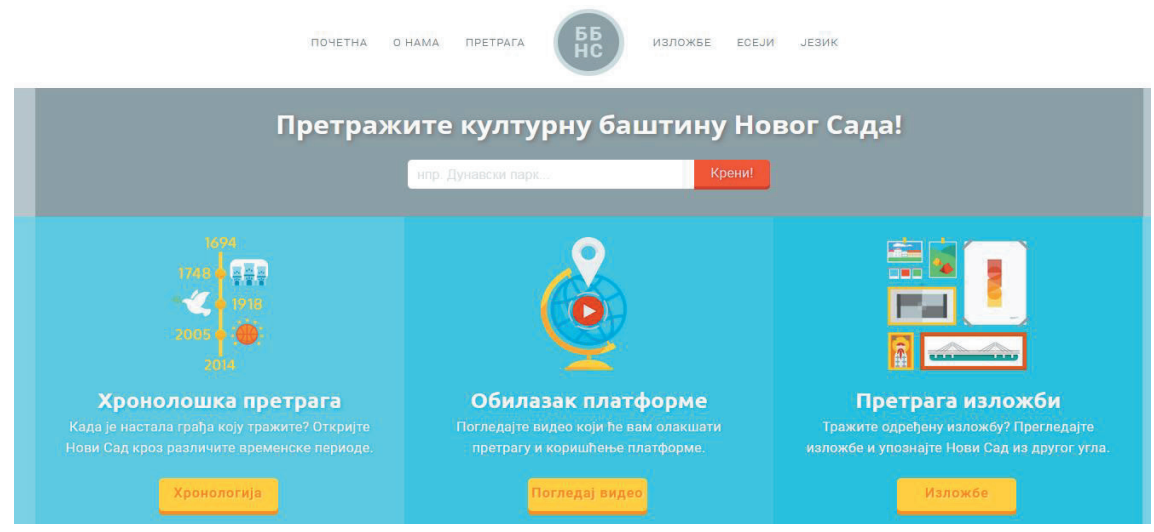

Izvor: www.bbns.rs

Postoje mobilne aplikacije koje su razvile kompanije, nezavisna udruženja (Šta je novosadski?) kao što je aplikacije "Priča se (p)o gradu Novom Sadu" koja predstavlja alternativni turistički vodič kroz Novi Sad. Slična aplikaciji iz Kanade, iBeacons, ona omogućava turistima i posetiocima grada da, dok šetaju gradom sa aktiviranom aplikacijom, slušaju brojne zanimljive priče o raznim delovima Novog Sada. U okviru aplikacije postoji nekoliko kategorija: Poznati Novosađani, Kulturno-istorijske priče i Lokalne legende. Takođe, korisnici aplikacije mogu poslušati i pročitati kako je izgrađen SPENS, šta znači taj akronim, ali i zašto su lipe u Zmaj Jovinoj ulici baš na tom mestu. Pored postojećih priča, aplikacija se obogaćuje i predlozima korisnika aplikacije koji mogu da podele svoje autentične priče, fotografije i tako doprinesu kvalitetnoj usluzi.

Slika 2. Aplikacija “"Priča se (p)o gradu Novom Sadu”

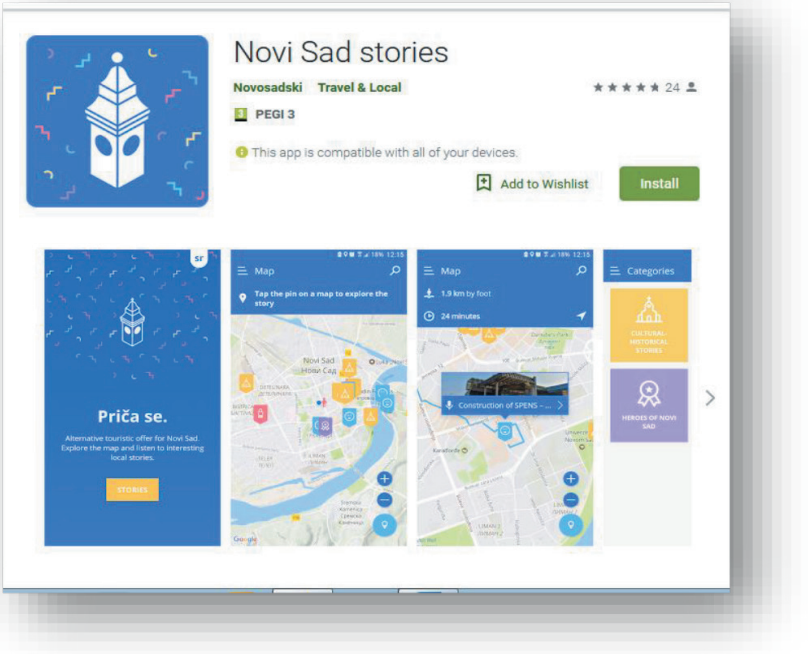

Izvor: https://www.novosadski.rs/

Takođe, korisnicima se na raspolaganju nalazi i inostrana aplikacija Cultural Trip (https://theculturetrip. $\mathrm{com} /$ ?s=novi\%20sad), koja u formi kratkih blog priča daje uvid u razna dešavanja i mogućnosti na jednoj destinaciji (i u njenom okruženju), a u čijoj bazi se nalazi i bogata ponuda grada Novog Sada. Ova aplikacija nudi brojne korisne informacije kako organizovati putovanje, izlete, preporuke restorana, ali daje predloge za posetu kulturnih događaja i mesta u gradu.

Imajući u vidu navedeno, preporuka bi bila da se posebna pažnja posveti digitalizaciji kulturnog nasleđa Novog Sada. Pored naloga na društvenim medijima (Facebook, Youtube, Instagram i sl.), veb sajta, značajnu 
upotrebnu vrednost mogu imati i savremene tehnologije poput zvaničnih mobilnih aplikacija (pored postojećih razvijenih od strane individualnih developera), virtuelnih tura (primera radi, turistička organizacija Galicije razvila je virtuelnu turu kulturne atrakcije Santjago de Kompostela koja turistima pruža sveobuhvatan pogled na prostor u i oko Katedrale (Živković et al, 2017)), interneta stvari, čija rešenja mogu da se koriste u svrhu upravljanja kulturnim objektima (senzorima se prati okolina, ali i enterijer objekta - temperatura, osvetljenje i kvalitet vazduha i sl.), ali i celim destinacijama (upravljanje saobraćajem, infrastrukturom, osvetljenjem, energetskom efikasnošću i sl.) (Brdar et al., 2018).

Koristeći iskustva i dobre prakse evropskih kulturnih gradova koji su već integrisali digitalnu komunikaciju u svoje marketinške strategije, grad Novi Sad bi revitalizacijom kulturnog nasleđa, rekonstrukcijom starih $i$ otvaranjem novih prostora namenjenih kulturi, razvijanjem medunarodne i medusektorske saradnje, podsticanjem interkulturnog dijaloga, decentralizacijom kulture, razvijanjem kulturne participacije gradana (http:// novisad2021.rs) postao prepoznatljiv na kulturnoj i turističkoj mapi Evrope i opravdao dobijene titule.

\section{ZAKLJUČAK}

Komparativna prednost kulturnog turizma se ogleda u jedinstvenom turističkom doživljaju koji se nudi. Dobro organizovane kulturne rute mogu da utiču na izgradnju imidža i promovisanje manje poznatih ili loše pozicioniranih turističkih destinacija. Naravno, prvo resursi zahtevaju i specifičnu komunikaciju, digitalne tehnologije koje su prepoznate kao moćan instrument u razvoju turizma a posebno u promovisanju i pozicioniranju kulturnog nasleđa. Strateški aspekt razvoja kulturnog turizma treba da bude podržan digitalizacijom kulturnog nasleđa koja bi omogućila razvoj inovativnih turističkih usluga. Zato je važno raditi na razvoju i primeni digitalnih veština kako bi se iskoristile mogućnosti digitalnih alata u poboljšanju konkurentnosti turističkog poslova, zatim razmena dobrih praksi i konsolidacija dijaloga/razmene između javnog i privatnog sektora, kao i unapređenje promocije i vidljivosti autentičnog kulturnog nasleđa i turističkog proizvoda u okvirima evropskog kulturnog prostora.

\section{LITERATURA}

Athena Plus (2014). Digital Cultural Heritage and Tourism, Recommendations for cultural institutions, version 1.0. dostupno na: http://www.athenaplus.eu/getFile.php?id=428 (pristupljeno 27.8.2018.)

Brdar I., Živković R., Gajić J., Stanković J. \& Kilibarda N. (2018).Smart turizam - mogućnost primene Interneta stvari u savremenom turističkom poslovanju. U: Sinteza - Singidunum University International Scientific Conference, 20. April 2018. (pp. 116-122). Belgrade: Univerzitet Singidunum.

Burzacca, P. \& Paterno, F., (2013). Remote Usability Evaluation of Mobile Web Applications. Conference: Proceedings of the 15th international conference on Human-Computer Interaction: human-centred design approaches, methods, tools, and environments - Volume Part I. DOI:10.1007/978-3-642-39232-0_27

Delgado, R. (2017). Strategies for Branding Cultural Tourism. Organizational Studies and Innovation Review. $3(2), 20-25$.

Du Cros, H. \& McKercher, B. (2015). Cultural Tourism, secong edition. New York: Routledge Taylor \& Francis Group.

Kolb, B. (2017). Tourism Marketing for cities and Towns, Using Social Media and Branding to Attract Tourists. 2nd edition. New York: Taylor \& Francis.

Lond, P. \& Morpeth, N.D. (2016).Tourism and the Creative Industries, Theories, policies and practice. London: Routledge, Taylor \& Francis Group.

Manrai , L.A., Manrai, A.K. \& DeLuca, J. (2017). Twenty Shades of Italy: An Analysis of its Cultural, Natural, and Dual Tourist Attractions with Implications for Global Tourism Marketing. Journal of Global Marketing, 30(5), 297-308. DOI:10.1080/08911762.2017.1323147

Maurer, C. (2015). Digital Divide and Its Potential Impact on Cultural Tourism. U: Katsoni V. (Ed.) Cultural Tourism in a Digital Era (pp. 231-241). Springer Proceedings in Business and Economics. 2015: Cham, Springer.

McCamley, C., \& Gilmore, A. (2016). Strategic marketing planning for heritage tourism: a conceptual model and empirical findings from two emerging heritage regions. Journal of Strategic Marketing, 26(2), 1-18. DOI:10.1080/0965254X.2016.1195859 
McKercher, B. \& Du Cros, H. (2012). Cultural Tourism: The Partnership Between Tourism and Cultural Heritage Management. London: Routledge, Taylor \& Francis Group.

Mihić, I.,, Makaran, E. \& Pandža, K. (2014). Digitalizacija u službi kulturnog turizma. Rijeka: Centar za industrijsku Baštinu.

Nosrati, F., Crippa, C. \& Detlor, B. (2018). Connecting people with city cultural heritage through proximity-based digital storytelling, Journal of Librarianship and Information Science, 50(3), 264-274. DOI:10. $1177 / 0961000618769972$

Živković R, Brdar, I, Gajić J. \& Stanković J. (2017). Digitalna promocija verskog turizma. U: SITCON 2017 (Singidunum International Tourism Conference), 8. Jun 2018. (pp. 132-139). Belgrade: Univerzitet Singidunum.

http://ec.europa.eu/growth/sectors/tourism/offer/cultural_en; pristupljeno 15.8.2018.

http://novisad2021.rs/bbns-digitalizacija-ubrojcavanje-k/; pristupljeno 15.8.2018.

http://novisad2021.rs/kulturna-strategija/; pristupljeno 23.8.2018.

http://novisad2021.rs/novisad; pristupljeno 15.9.2018.

http://novisad2021.rs/prosle-i-buduce-prestonice/?jez=lat; pristupljeno 25.8.2018.

http://novisad2021.rs; pristupljeno 13.9.2018.

http://www.culturaltourism-network.eu/; pristupljeno 27.8.2018.

http://www2.unwto.org/webform/survey-big-data-and-cultural-tourism; pristupljeno 15.8.2018.

https://ec.europa.eu/docsroom/documents/29223; pristupljeno 15.8.2018.

https://ec.europa.eu/programmes/creative-europe/actions/capitals-culture_en; pristupljeno 15.8.2018.

https://europa.eu/cultural-heritage/about; pristupljeno 15.8.2018.

https://theculturetrip.com/?s=novi\%20sad; pristupljeno 15.9.2018.

https://www.exitfest.org/sr/news/sve-o-exitu-201;pristupljeno 15.9.2018.

www.bbns.rs; pristupljeno 15.9.2018.

www.unesco.org;pristupljeno 15.8.2018.

\title{
THE IMPORTANCE OF USING DIGITAL COMMUNICATION IN THE PROMOTION OF CULTURAL HERITAGE - THE EXAMPLE OF THE CITY OF NOVI SAD
}

\begin{abstract}
:
Cultural tourism is considered to be the fastest growing segment of the tourism market and especially in Europe. Culture is increasingly used as a promotional tool which provides a rich authentic tourist offer. New information technology IT and market trends dictate new ways of communication between the market and the target group so that digital marketing allows for a more direct and more active interaction between tourists, tourism products and destinations. The aim of this paper is to show the relation of culture, cultural heritage and tourism development with the support of modern marketing communications. Culture as the social heritage of a particular group of people, communities or societies in recent decades strongly influences the development of tourism in many destinations, and new IT and market trends dictate new ways of communication between the market and the target group. Digital marketing provides interactivity and offers personalized services to tourists. The paper presents an example of a development project, namely an example of digital communication with informational "connected" tourists, that is, the importance of using digital media in order to achieve a competitive advantage and better position the cultural offer of Novi Sad in global tourist market.
\end{abstract}

Keywords:

Cultural Heritage, Tourism, Digital Marketing, Social Media 